Sari Pediatri, Vol. 4, No. 2, September 2002: 67 - 73

\title{
Terapi Inhalasi pada Asma Anak
}

\author{
Bambang Supriyatno*, Heda Melinda D Nataprawira**
}

Pemberian obat pada asma dapat berbagai macamn cara yaitu parenteral, per oral, atau perinhalasi. Pemberian per inhalasi adalah pernberian obat secara langsung ke dalam saluran nafas melalui penghisapan. Pernberian obat secara inhalasi mempunyai beberapa keuntungan yaitu obat bekerja langsung pada saluran nafas, onset kerjanya cepat, dosis obat yang digunakan kecil, serta efek samping yang minimal karena konsentrasi obat di dalam darah sedikit atau rendah. Pemberian aerosol yang ideal adalah dengan alat yang sederhana, mudah dibawa, tidak mahal, secara selektif mencapai saluran nafas bawah, hanya sedikit yang tertinggal di saluran nafas atas serta dapat digunakan oleh anak, orang cacat atau orang tua. Namun keadaan ideal tersebut tidak dapat sepenuhnya tercapai dengan adanya beberapa keuntungan dan kerugian masing-masing jenis alat terapi inhalasi. Terapi inhalasi dapat diberikan dengan inhaler dosis terukur (metered dose inhaler $=M D I$ ), $M D I$ dengan bantuan spacer, nebulizer, intermitten positive pressure breathing, rotahaler, atau diskhaler. Jenis terapi inhalasi di atas mempunyai keuntungan dan kerugian masing-masing. Keberhasilan terapi inhalasi ditentukan oleh indikasi, cara pemilihan obat, jenis obat, dan cara pemberiannya. Pada asma anak, baik tatalaksana serangan (Pereda, reliever) maupun tatalaksana jangka panjang (pengendali, controller) sangat dianjurkan penggunaan secara inhalasi. Penggunaan terapi inhalasi merupakan pilihan tepat pada asma karena banyak manfaat yang didapat seperti onset kerjanya cepat, dosis obat kecil, efek samping minimal, dan langsung mencapai target. Namun demikian, terapi inhalasi ini mempunyai beberapa kendala yaitu tehnik dan cara pemberian yang kurang tepat sehingga masih banyak yang tidak menggunakannya. Dengan mengetahui hal di atas diharapkan pengobatan asma mencapai kemajuan yang cukup berarti.

Kata kunci: terapi inhalasi, asma anak

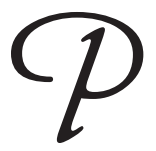

engobatan asma bertujuan untuk menghentikan serangan asma secepat mungkin serta mencegah serangan berikutnya ataupun bila timbul serangan kembali diusahakan agar serangannya tidak berat. Untuk mencapai tujuan tersebut perlu diberi obat bronkodilator pada saat

Dr. Heda Melinda D. Nataprawira Sp.A, Subbagian Pulmonologi Bagian Ilmu Kesehatan Anak, FK Unpad-RSHS Bandung.

Alamat Korespondensi:

Dr. Bambang Supriyatno, Sp.A.

Subbagian Pulmonologi Bagian Ilmu Kesehatan Anak FKUI-RSCM Jl. Salemba no. 6, Jakarta 10430.

Telepon: 021-3100669. Fax: 021-390 7743 serangan dan atau obat antiinflamasi sebagai obat pengendali untuk menekan reaksi inflamasi yang terjadi. ${ }^{1,2}$

Pemberian obat pada asma dapat dengan berbagai macam cara yaitu parenteral, oral, atau inhalasi. Pengobatan atau terapi inhalasi adalah pemberian obat secara langsung ke dalam saluran napas melalui penghisapan dalam bentuk aerosol atau serbuk ( $d r y$ powder). Sebenarnya prinsip terapi inhalasi telah digunakan sejak dahulu misalnya penggunaan asap untuk pengobatan batuk. Penggunaan aerosol sebagai pengobatan inhalasi pertama kali dikenalkan oleh Schneider dan Waltz ${ }^{3}$ pada tahun 1829 dan dengan perkembangan ilmu dan teknologi, terapi inhalasi berkembang dengan pesat. 
Pada awalnya bahan yang digunakan tidak turut dipertimbangkan pengaruhnya terhadap lingkungan tetapi akhir-akhir ini mulai dikembangkan penggunaan propelan yang bersahabat dengan lingkungan yaitu yang tidak merusak lapisan ozon. . $^{4,5}$

Terapi inhalasi pada asma dewasa telah banyak digunakan dan keberhasilannya cukup baik. Penggunaannya pada anak belum banyak atau apabila diberikan seringkali cara dan jenis obat inhalasi tidak tepat atau bahkan anak atau orang tua tidak cukup mengerti kapan dan bagaimana penggunaannya untuk pengobatan asma anaknya. Selain itu jenis terapi inhalasi yang dipasarkan saat ini dibuat untuk orang dewasa yang kemudian digunakan juga untuk anak. Untuk menunjang keberhasilan penggunaan pada anak diperlukan pengetahuan mengenai perbedaan antara dewasa dan anak dalam hal fisiologi dan sistem koordinasi serta tentang teknik inhalasi yang optimal sehingga penggunaan terapi inhalasi dapat lebih dipahami. ${ }^{7,8,9}$

\section{Prinsip terapi inhalasi}

Prinsip farmakologis terapi inhalasi yang ideal untuk penyakit saluran napas adalah obat dapat sampai pada organ target dengan menghasilkan partikel aerosol berukuran optimal agar terdeposisi di paru, onset kerjanya cepat, dosis obat kecil, efek samping minimal karena konsentrasi obat di dalam darah sedikit atau rendah, mudah digunakan, serta efek terapeutik tercapai yang ditandai dengan tampaknya perbaikan klinis. ${ }^{7,8,9}$ Meskipun saluran napas mempunyai beberapa mekanisme antara lain refleks batuk, bersin serta klirens mukosilier yang akan melindungi terhadap masuk dan mengendapnya partikel obat sehingga akan mengeliminasi obat inhalasi. Namun dengan memperhatikan metode untuk menghasilkan aerosol serta cara penyampaian/delivery obat yang akan mempengaruhi ukuran partikel yang dihasilkan dan jumlah obat yang mencapai berbagai tempat di saluran napas maka diharapkan obat terdeposisi secara efektif. ${ }^{6}$

Ukuran partikel akan mempengaruhi sampai sejauh mana partikel menembus saluran napas. Partikel berukuran $>15 \mathrm{~mm}$ tersaring oleh filtrasi rambut hidung sedangkan $>10 \mathrm{~mm}$ akan mengendap di hidung dan nasofaring. Partikel yang besar ini terutama mengendap karena benturan inersial bila terdapat aliran udara yang cepat disertai perubahan arah atau arus turbulen. Partikel berukuran 0,5 - $5 \mathrm{~mm}$ akan mengendap secara sedimentasi karena gaya gravitasi sedangkan partikel berukuran $<0,1 \mathrm{~mm}$ akan mengendap karena gerak Brown. Dengan demikian untuk mendapatkan manfaat obat yang optimal, obat yang diberikan secara inhalasi harus dapat mencapai tempat kerjanya di dalam saluran pernapasan. Bentuk aerosol yang digunakan yaitu suspensi partikel di dalam gas, dan partikel dalam aerosol yang mempunyai ukuran berkisar 2-10 $\mathrm{Im}^{7}$ atau 1-7 İm. ${ }^{9}$ Penelitian lainnya mendapatkan bahwa partikel berukuran 1-8 Ïm mengalami benturan dan pengendapan di saluran nafas besar, kecil, dan alveoli. ${ }^{10,11}$

\section{Faktor yang mempengaruhi delivery aerosol pada anak}

Dengan memperhatikan kebutuhan anak maka diperlukan pengetahuan bahwa masa anak merupakan masa dengan adanya perubahan nyata pada perkembangan fisik, intelektual, dan sosial pada masa prasekolah. Beberapa faktor yang mempengaruhi delivery aerosol pada anak antara lain: ${ }^{9}$

1. Perubahan anatomi

Bagaimana efek perubahan anatomi pada awal tahun kehidupan tidak jelas. Saluran pernapasan anak relatif lebih kecil dibandingkan dewasa sehingga aliran udara inspirasi lebih rendah yang menyebabkan deposit obat terutama pada saluran pernapasan sentral.

2. Kompetensi

Kompetensi atau kemampuan anak merupakan faktor sangat penting dalam delivery obat. Anak kecil tidak mempunyai kompetensi untuk melakukan manuver inhalasi yang kompleks. Alat/ jenis inhalasi yang tersedia dan dipasarkan saat ini dibuat untuk orang yang bisa melakukan inhalasi melalui mulut waktu melakukan manuver inhalasi yang kompleks, misalnya pressured metered dosed inhalers (pMDIs). Anak sekolah sudah dapat melakukan usaha inspirasi maksimal yang diperlukan untuk menggunakan alat inhalasi jenis dry powder inhaler (DPI) dan hanya sedikit yang bisa menggunakan pMDI.

3. Pola pernapasan bayi dan anak akan mempengaruhi seberapa banyak aerosol yang diinhalasi ke dalam paru-paru. Pernapasan pada bayi dan anak menunjukkan volume pernapasan tidal yang kecil 
sehingga mengurangi delivery obat, pola pernapasan bervariasi luas dengan aliran udara inspirasi (inspiratory flow rates $=$ IFR) bervariasi antara 0 sampai $40 \mathrm{~L} /$ menit. Aliran udara yang cepat akan menyebabkan deposit pada saluran napas yang lebih proksimal.

4. Anak yang menangis mempunyai IFR tinggi dan terjadi pernapasan mulut sehingga seharusnya akan meningkatkan delivery obat ke paru-paru. Namun, kenyataannya jumlah obat yang diinhalasi ke paruparu berkurang karena kurang baiknya masker muka menempel dan pada waktu menangis pernapasan pendek dan cepat.

\section{Jenis terapi inhalasi}

Pemberian aerosol yang ideal adalah dengan alat yang sederhana, mudah dibawa, tidak mahal, secara selektif mencapai saluran napas bawah, hanya sedikit yang tertinggal di saluran napas atas serta dapat digunakan oleh anak, orang cacat, atau orang tua. Namun keadaan ideal tersebut tidak dapat sepenuhnya tercapai dan masing-masing jenis alat terapi inhalasi mempunyai beberapa keuntungan dan kerugian. Hingga saat ini dikenal 3 sistem inhalasi yang digunakan dalam klinik sehari-hari yaitu, ${ }^{7}$

1. Nebuliser

2. Metered dosed inhaler aerosol (dengan atau tanpa spacer / alat penyambung)

3. Dry powder inhaler

\section{Nebuliser}

Alat nebuliser dapat mengubah obat yang berbentuk larutan menjadi aerosol secara terus menerus dengan tenaga yang berasal dari udara yang dipadatkan atau gelombang ultrasonik sehingga dalam prakteknya dikenal 2 jenis alat nebuliser yaitu ultrasonic nebuliser dan jet nebuliser. Hasil pengobatan dengan nebuliser lebih banyak bergantung pada jenis nebuliser yang digunakan. Terdapat nebuliser yang dapat menghasilkan partikel aerosol terus menerus ada juga yang dapat diatur sehingga aerosol hanya timbul pada saat penderita melakukan inhalasi sehingga obat tidak banyak terbuang. ${ }^{7,8,9,12,13}$ Keuntungan terapi inhalasi menggunakan nebuliser adalah tidak atau sedikit memerlukan koordinasi pasien, hanya memerlukan pernafasan tidal, beberapa jenis obat dapat dicampur (misalnya salbutamol dan natrium kromoglikat). Kekurangannya adalah karena alat cukup besar, memerlukan sumber tenaga listrik dan relatif mahal. ${ }^{7}$

- Ultrasonic nebuliser

Alat ini menghasilkan aerosol melalui osilasi frekuensi tinggi dari piezo-electric crystal yang berada dekat larutan dan cairan memecah menjadi aerosol. Keuntungan jenis nebuliser ini adalah tidak menimbulkan suara bising dan terus menerus dapat mengubah larutan menjadi aerosol sedangkan kekurangannya alat ini mahal dan memerlukan biaya perawatan lebih besar.

\section{- Jet nebuliser}

Alat ini paling banyak digunakan banyak negara karena relatif lebih murah daripada ultrasonic nebuliser. Dengan gas jet berkecepatan tinggi yang berasal dari udara yang dipadatkan dalam silinder ditiupkan melalui lubang kecil dan akan dihasilkan tekanan negatif yang selanjutnya akan memecah larutan menjadi bentuk aerosol. Aerosol yang terbentuk dihisap pasien melalui mouth piece atau sungkup. Dengan mengisi suatu tempat pada nebuliser sebanyak $4 \mathrm{ml}$ maka dihasilkan partikel aerosol berukuran < 5 Ïm, sebanyak 60-80\% larutan nebulisasi akan terpakai dan lama nebulisasi dapat dibatasi. Dengan cara yang optimal maka hanya $12 \%$ larutan akan terdeposit di paru-paru. ${ }^{7}$ Bronkodilator yang diberikan dengan nebuliser memberikan efek bronkodilatasi yang bermakna tanpa menimbulkan efek samping. ${ }^{12}$

\section{Metered dose inhaler (MDI)}

Metered dose inhaler (MDI) atau inhaler dosis terukur merupakan cara inhalasi yang memerlukan teknik inhalasi tertentu agar sejumlah dosis obat mencapai saluran pernafasan. Pada inhaler ini bahan aktif obat disuspensikan dalam kurang lebih $10 \mathrm{ml}$ cairan pendorong (propelan) dan yang biasa digunakan adalah kloroflurokarbon (chlorofluorocarbon $=$ CFC) pada tekanan tinggi. Akhir-akhir ini mulai dikembangkan penggunaan bahan non-CFC yaitu hidrofluroalkana (HFA) yang tidak merusak lapisan ozon. ${ }^{6,14,15}$ Propelan mempunyai tekanan uap tinggi sehingga di dalam tabung (kanister) tetap berbentuk cairan. Bila kanister ditekan, aerosol disemprotkan keluar dengan kecepatan tinggi yaitu $30 \mathrm{~m} /$ detik dalam bentuk droplet dengan 
dosis tertentu melalui aktuator (lubang). Pada ujung aktuator ukuran partikel berkisar $35 \mathrm{Im}$, pada jarak 10 $\mathrm{cm}$ dari kanister besarnya menjadi 14 Ïm, dan setelah propelan mengalami evaporasi seluruhnya ukuran partikel menjadi 2,8-4,3 Ïm. Dengan teknik inhalasi yang benar maka $80 \%$ aerosol akan mengendap di mulut dan orofarings karena kecepatan yang tinggi dan ukurannya besar, $10 \%$ tetap berada dalam aktuator, dan hanya sekitar 10\% aerosol yang disemprotkan akan sampai ke dalam paru-paru. ${ }^{7}$

Pada cara inhalasi ini diperlukan koordinasi antara penekanan kanister dengan inspirasi napas. ${ }^{9} 16$ Untuk mendapatkan hasil optimal maka pemakaian inhaler ini hendaklah dikerjakan sebagai berikut:

- terlebih dahulu kanister dikocok agar obat tetap homogen, lalu tutup kanister dibuka

- inhaler dipegang tegak kemudian pasien melakukan ekspirasi maksimal secara perlahan

- mulut kanister diletakkan diantara bibir, lalu bibir dirapatkan dan dilakukan inspirasi perlahan sampai maksimal

- pada pertengahan inspirasi kanister ditekan agar obat keluar

- pasien menahan nafas 10 detik atau dengan menghitung 10 hitungan pada inspirasi maksimal

- setelah 30 detik atau 1 menit prosedur yang sama diulang kembali

- setelah proses selesai, jangan lupa berkumur untuk mencegah efek samping.

Langkah-langkah di atas harus dilaksanakan sebelum pasien menggunakan obat asma jenis MDI. Langkah di atas sering tidak diikuti sehingga pengobatan asma kurang efektif dan timbul efek samping yang tidak diinginkan. Beberapa ahli mengidentifikasi beberapa kesalahan yang sering dijumpai antara lain kurangnya koordinasi pada saat menekan kanister dan saat menghisap, terlalu cepat inspirasi, tidak berhenti sesaat setelah inspirasi, tidak mengocok kanister sebelum digunakan, dan terbalik pemakaiannya. Kesalahankesalahan di atas umumnya dilakukan oleh anak yang lebih muda, manula, wanita, dan penderita dengan sosial ekonomi dan pendidikan yang rendah. ${ }^{3,9,16,17}$

\section{MDI dengan spacer}

Spacer (alat penyambung) akan menambah jarak antara aktuator dengan mulut sehingga kecepatan aerosol pada saat dihisap menjadi berkurang dan akan dihasilkan partikel berukuran kecil yang berpenetrasi ke saluran pernafasan perifer. Hal ini merupakan kelebihan dari penggunaan spacer karena mengurangi pengendapan di orofaring. Spacer ini berupa tabung (dapat bervolume $80 \mathrm{ml}$ ) dengan panjang sekitar 10$20 \mathrm{~cm}$, atau bentuk lain berupa kerucut dengan volume 700-1000 ml. Untuk bayi dianjurkan menggunakan spacer volume kecil (babyhaler) agar aerosol yang dihasilkan lebih mampat sehingga lebih banyak obat akan terinhalasi pada setiap inspirasi. Beberapa alat dilengkapi dengan katup satu arah yang akan terbuka saat inhalasi dan akan menutup pada saat ekshalasi misalnya Nebuhaler (Astra), Volumatic (A\&H) ${ }^{6,7,12,13,21}$ Pengendapan di orofaring akan berkurang yaitu sekitar $5 \%$ dosis yang diberikan bila digunakan spacer dengan katup satu arah. Pada spacer tanpa katup satu arah, pengendapan di orofaring sekitar 8-60\% dosis. Dengan penggunaan spacer, deposit pada paru akan meningkat menjadi 20\% dibandingkan tanpa spacer. Penggunaan spacer ini sangat menguntungkan pada anak karena pada anak koordinasinya belum baik. Dengan bantuan spacer, koordinasi pada saat menekan kanister dengan saat penghisapan dapat dikurangi atau bahkan tidak memerlukan koordinasi. ${ }^{7,13,22}$ Apabila spacer ini tidak tersedia maka sebagai penggantinya bisa digunakan spacer sederhana yang murah dan mudah dibuat yaitu dari plastic coffee cup yang dilubangi dasarnya untuk tempat aerosol. Cara ini sudah terbukti bermanfaat hanya untuk bronkodilator dan belum dibuktikan berguna untuk natrium kromoglikat dan steroid. ${ }^{7}$

\section{Easybaler}

Easyhaler adalah inhaler serbuk multidosis yang merupakan alternatif dari MDI. Komponennya terdiri dari plastik dan cincin stainless steel dan mengandung serbuk untuk sekurang-kurangnya 200 dosis. Masing-masing dosis obat dihitung secara akurat dengan cara menekan puncak alat (overcap) yang akan memutari silinder (metering cylindric) pada bagian bawah alat tersebut. Cekungan dosis berisi sejumlah obat berhubungan langsung dengan mouth piece. Saluran udara ke arah mouthpiece berbentuk corong dengan tujuan untuk mengoptimalkan deposisi obat di saluran napas. Terdapat takaran dosis yang berguna untuk memberi informasi kepada pasien mengenai sisa dosis obat. Pelindung penutup berguna untuk mencegah kelembaban. Partikel obat yang halus $(<10$ İ) sulit untuk melayang jauh dan cenderung untuk menggumpal, oleh karena itu zat 
aktif tersebut dicampur dengan sejumlah kecil laktosa yang berperan sebagai pembawa. Pada easyhaler ukuran partikel laktosa cukup besar untuk deposit di saluran napas bawah sehingga diharapkan akan jatuh di orofaring. Keadaan ini mempunyai keuntungan untuk memberitahukan pada penderita bahwa obatnya benar terhisap dengan rasa manis di mulut. ${ }^{22}$

\section{Dry Powder Inhaler}

Pada awalnya di tahun 1957 jenis inhaler ini digunakan untuk delivery serbuk antibiotik. Selanjutnya banyak penelitian uji klinis yang menunjukkan bahwa DPI bisa digunakan untuk pengobatan asma anak. Dalam perkembangannya pada tahun 1970 dibuat inhaler yang hanya memuat serbuk kering dosis tunggal seperti misalnya spinhaler dan rotahaler, dan akhir tahun 1980 diperkenalkan inhaler yang memuat multiple dosis yaitu yang dikenal dengan diskhaler (8 dosis) dan turbuhaler. Beberapa tahun terakhir ini diperkenalkan diskus (di Inggris dikenal dengan accuhaler) yang memuat 60 dosis dan dapat dipergunakan untuk 1 bulan terapi. ${ }^{6}$ Inhaler jenis ini tidak mengandung propelan sehingga mempunyai kelebihan dari MDI. Penggunaan obat serbuk kering pada DPI memerlukan inspirasi yang cukup kuat. Pada anak yang kecil hal ini sulit dilakukan mengingat inspirasi kuat belum dapat dilakukan, sehingga deposisi obat pada saluran pernafasan berkurang. Pada anak yang lebih besar, penggunaan obat serbuk ini dapat lebih mudah, karena kurang memerlukan koordinasi dibandingkan dengan MDI. Dengan cara ini deposisi obat di dalam paru lebih tinggi dan lebih konstan dibandingkan MDI sehingga dianjurkan diberikan pada anak di atas 5 tahun. Cara DPI ini tidak memerlukan spacer sebagai alat bantu sehingga mudah dibawa dan dimasukkan ke dalam saku. Hal ini yang juga memudahkan pasien dan lebih praktis. ${ }^{6,9}$

\section{Terapi inhalasi pada asma}

Pada tata laksana asma harus dibedakan dua hal penting yaitu tata laksana serangan dan tata laksana jangka panjang. Seorang anak yang telah didiagnosis asma harus ditentukan klasifikasinya. Berdasarkan Konsensus Nasional Penanganan Asma (KNAA) klasifikasi asma di luar serangan adalah asma episodik jarang, episodik sering, dan asma persisten. ${ }^{23}$ Pada asma episodik jarang, tidak diperlukan obat pengendali (controller) untuk tata laksana jangka panjangnya sedangkan pada asma episodik sering dan asma persisten harus diberikan obat pengendali. Obat pengendali dari golongan antiinflamasi yang sering digunakan adalah budesonid, beklometason dipropionat, flutikason, dan golongan natrium kromoglikat. ${ }^{23}$ Bila terjadi serangan maka digunakan obat pereda (reliever). Obat yang sering digunakan yaitu golongan bronkodilator seperti metilsantin (teofilin), $\beta_{2}$ agonis, dan ipratropium bromida. Obat-obat ini dapat digunakan secara oral, parenteral, dan inhalasi, ${ }^{1,2,7,23}$ tetapi untuk metilsantin pemberian secara oral dan intravena lebih dipilih daripada inhalasi karena obat ini menyebabkan iritasi saluran napas. ${ }^{7}$

Telah diketahui secara luas bahwa obat antiinflamasi yang sering digunakan adalah golongan steroid. Mekanisme dasar asma adalah terjadinya reaksi inflamasi sehingga pengendalian dengan obat antiinflamasi sangat dianjurkan pada asma episodik sering dan persisten. Namun harus disadari penggunaan kortikosteroid jangka panjang peroral atau parenteral dapat mengganggu tumbuh kembang anak secara keseluruhan selain efek samping lain yang mungkin timbul seperti hipertensi dan moon-face. Untuk itu pemberian inhalasi sangat dianjurkan. Jenis terapi inhalasi yang diberikan dapat disesuaikan dengan usia pasien dan patokan ini tidak berlaku secara kaku. Patokan yang diajukan oleh Dolovich dan Everard ${ }^{9}$ di bawah ini dapat dipakai sebagai acuan.

Tabel Nebuliser pada kelompok umur

\begin{tabular}{lll}
\hline $\begin{array}{l}\text { Umur } \\
\text { (tahun) }\end{array}$ & Pereda & Pengendali \\
\hline $0-3$ & $\bullet$ pMDI / dengan spacer nebuliser & $\bullet$ pMDI / dengan spacer nebuliser \\
$3-5$ & $\bullet$ pMDI / dengan spacer nebuliser & $\bullet$ pMDI / dengan spacer nebuliser \\
& & DPI (?) \\
$>5$ & $\bullet$ pMDI / dengan spacer & $\bullet$ pMDI / dengan spacer \\
& DPI nebuliser & DPI \\
\hline
\end{tabular}

Dikutip dari: Dolovich dan Everard ${ }^{9}$ dengan modifikasi 
Bagaimana sebenarnya penggunaan obat inhalasi pada asma anak dapat diterangkan sebagai berikut:

\section{Tata laksana saat serangan}

Pada saat serangan obat yang digunakan adalah obat golongan bronkodilator dan yang sering digunakan yaitu $\beta_{2}$ agonis yang dapat diberikan sendiri atau bersama-sama dengar'ipratropium bromid. Pada serangan asma yang ringan obat inhalasi yang diberikan hanya $\beta_{2}$ agonis saja meskipun ada juga yang menambahkan dengan ipratropium bromida. Schuch dkk dalam penelitiannya mendapatkan bahwa dengan menggunakan $\beta_{2}$ agonis saja dapat meningkatkan $\mathrm{FEV}_{1}$ dan menghilangkan gejala serangannya, sedangkan penambahan ipratropium bromida akan meningkatkan FEV1 yang lebih tinggi lagi. ${ }^{24}$ Pada serangan asma yang berat, KNAA menganjurkan pemberian $\beta_{2}$ agonis bersama-sama dengan ipratropium bromid. ${ }^{23}$ Pemberian cara nebuliser untuk usia 18 bulan- 4 tahun dianjurkan menggunakan mouthpiece daripada masker muka untuk menghindarkan deposisi obat di muka dan mata. ${ }^{7}$ Apabila dengan pemberian inhalasi obat tersebut serangan asma tidak teratasi/sedikit perbaikan maka dapat diberikan steroid sistemik. Pemberian steroid sistemik perlu diperhatikan pada anak dengan serangan asma yang sering karena anak ini berisiko mengalami efek samping akibat pemberian steroid sistemik berulang kali seperti supresi adrenal, gangguan pertumbuhan tulang, dan osteoporosis. Untuk mengurangi pemberian steroid oral berulang, maka sebagai alternatifnya dapat diberikan inhalasi budesonid dosis tinggi (1600 mg perhari) pada anak yang serangan asmanya tidak teratasi dengan penanganan inhalasi $\beta_{2}$ agonis di rumah dan mereka belum/tidak perlu perawatan di rumah sakit. ${ }^{25}$

Penggunaan obat pereda secara inhalasi pada serangan asma sangat bermanfaat dan justru sangat dianjurkan, namun demikian penggunaannya masih belum banyak. Hal ini dimungkinkan karena penggunaannya yang belum banyak diketahui dan harga obat masih mahal. Hal ini berlaku bukan hanya di Indonesia, tetapi juga berlaku di negara maju. Penggunaannya pada orang dewasa lebih banyak dibandingkan dengan anak. ${ }^{1,21,26}$

\section{Tata laksana di luar serangan}

Obat inhalasi di luar serangan asma hanya diberikan apabila memerlukan obat pengendali; yang biasa digunakan adalah natrium kromoglikat dan golongan steroid. Natrium kromoglikat menurut KNAA diberikan apabila termasuk asma episodik sering sedangkan penggunaan steroid dapat diberikan pada asma episodik sering dan asma persisten. Natrium kromoglikat menunjukkan absorbsi yang tidak baik sehingga hanya efektif bila diberikan secara inhalasi. Obat ini tersedia dalam nebuliser solution, serbuk aerosol dan aerosol dengan dosis $20 \mathrm{mg}$ untuk nebuliser atau $2 \mathrm{mg}$ secara aerosol. ${ }^{7}$

Penggunaan steroid pada asma anak masih jarang mengingat samping yang mungkin ditimbulkan. Namun beberapa peneliti telah membuktikan bahwa dengan penggunaan yang tepat dengan dosis, cara, dan jenis yang sesuai maka efek samping dapat dikurangi. Penggunaan obat inhalasi yang salah akan meningkatkan efek samping seperti jamur/kandidiasis di daerah mulut, suara serak, dan efek lainnya. Dengan inhalasi sebagian obat juga akan beredar ke seluruh tubuh melalui sistem gastrointestinal dan selanjutnya akan dielimininasi melalui hati sehingga dalam peredaran sistemik kadarnya berkurang. Obat yang baik adalah yang dapat elimininasi tubuh dengan baik artinya kadar di dalam sirkulasi menjadi kecil. Penggunaan steroid inhalasi pada asma episodik sering dan asma persisten memerlukan waktu yang lama dan dosis yang mungkin bervariasi. Pada awal pengobatan dapat diberikan dosis tinggi (400-800 mg per hari) dan diturunkan secara perlahan sampai tercapai dosis optimum untuk anak tersebut dan dipertahankan pada dosis optimum untuk beberapa lama dan kemudian diturunkan secara bertahap sampai pada akhirnya kalau memungkinkan tidak digunakan sama sekali. Penggunaan waktu lama (sekitar 2-3 tahun) dengan dosis $400 \mathrm{mg}$ perhari tidak mengganggu proses tumbuh kembang anak. ${ }^{27,28}$ Untuk bayi dan anak berusia di bawah 4 tahun yang memerlukan steroid inhalasi dapat digunakan suspensi budesonid inhalasi (pulmicort respules) yang diberikan dengan nebuliser. ${ }^{29,30}$ Jadi penggunaan steroid inhalasi dapat lebih aman apabila kita mengetahui cara penggunaannya.

\section{Kesimpulan}

Terapi inhalasi merupakan pilihan tepat untuk asma karena banyak manfaat yang didapat seperti onset kerjanya cepat, dosis obat kecil, efek samping minimal, dan langsung mencapai target. Beberapa kendala terapi 
inhalasi berupa teknik dan cara pemberian yang kurang tepat menyebabkan masih banyak yang tidak menggunakannya. Untuk mengatasi masalah di atas perlu diketahui indikasi, cara pemilihan obat, jenis, cara pemberian, dan perlu berulang kali mengontrol apakah anak menggunakannya dengan tepat, bahkan orang tua dianjurkan mencoba alat inhalasi yang diberikan untuk anaknya. Dengan mengetahui hal tersebut di atas maka diharapkan pengobatan asma dapat mencapai kemajuan yang cukup berarti.

\section{Daftar Pustaka}

1. Lenfant C, Khaltaev N. Global initiative for asthma. NHLBI/WHO Workshop Report 1995

2. Warner JO, Naspitz CK. Third International Pediatric Consensus Statement on the Management of Childhood Asthma. Pediatr Pulmonol 1998; 25:1-17.

3. Huchon, G. Metered dose inhalers past and present: Advantages and limitations. Eur Respir Rev 1997; 7:26-8.

4. Matthys H. CFCs and their effect on the ozone layer: the Montreal Protocol and consequences for physicians. Eur Respir Rev 1997; 7:29-31.

5. June D. Achieving the change: challenges and successes in the formulation of CFC-free MDIs. Eur Respir Rev 1997; 7:32-4.

6. Newman SP. New aerosol delivery system. Dalam: Barnes PJ, Grunstein MM, Leff AR, Woolcock AJ, Asthma. Philadelphia: Lippincott-Raven, 1997. h. 1805-15.

7. Reiser J dan Warner JO. Inhalation treatment for asthma. Arch Dis Child 1986; 61:88-94.

8. Barry PW, Fouroux B, Pederson S, O'Callaghan C. Nebulizers in childhood. Eur Respir Rev 2000; 10: $527-$ 35.

9. Dolovich MB, Everard ML. Delivery of aerosols to children: devices and inhalation techniques. Dalam: Naspitz C, Szefler SJ, Tinkelman D, Warner JO. Textbook of pediatric asthma. An International Perspective. London: Martin Dunitz Ltd 2001. h. 327-46.

10. Malmstrom K, Sorva R, Silvasti M. Application and efficacy of the multidose powder inhaler, easyhaler, in children with asthma. Pediatr Allergy Immunol 1999; 10:66-70.

11. Kanner RE, Kanter LJ, Dwork P. A comparison of drug delivery from a metered-dose inhaler plus an inspiratory flow control device with a metered-dose inhaler plus a spacer device. J Allergy Clin Immunol 1997; 99:853-4.

12. Bertrand P, Aranibar H, Castro E, Sanchez I. Efficacy of nebulized epinephrine versus salbutamol in hospitalized infants with bronchiolitis. Pediatr Pulmonol 2001; 31:284-8.

13. Freenhandler M, Asperen PPV. Nebuhaler versus nebulizer in children with acute asthma. Br Med J 1984; 288: 1873-4.

14. Leach C. Safety assessment of the HFA propellant and the new inhaler. Eur Respir Rev 1997; 7:35-6.
15. Bleecker E. Clinical reality: the safety and efficacy of the world's first CFC-free MDI. Eur Respir Rev 1997; 7:37-9.

16. Kamps AWA, van Ewijk B, Roorda RJ, Brand PLP. Poor inhalation technique, even after inhalation instructions, in children with asthma. Pediatr Pulmonol 2000; 29:39-42.

17. Fok TF, Lam K, Cheung Ng P, dkk. Aerosol delivery to non-ventilated infants by metered-dose inhaler: should a valved spacer be used? Pediatr Pulmonol 1997; 24:204-12.

18. Pederson S. Aerosol treatment of bronchoconstriction in children, with or without a tube spacer. N Engl J Med 1983; 308:1328-30.

19. Barry PW. In vitro comparison of the amount of salbutamol available for inhalation from different formulations used with different spacer devices. Eur Respir J 1997; 10:1345-8.

20. Rubilar L, Castro-Rudriguez JA, Girardi G. Randomized trial of salbutamol via metered-dose inhaler with spacer versus nebulizer for acute wheezing in children less than 2 years of age. Pediatr Pulmonol 2000; 29:264-9.

21. Nikander K, Turpeinem M, Wolmer P. Evaluation of pulsed and breath-syncrinized nebulization of budesonide as a means of reducing nebulizer wastage of drug. Pediatr Pulmonol 2000; 29:120-6.

22. Ahonen A, Leinonen M, Pesonen MR. Patient satisfaction with easyhaler compared with other inhalation system in the treatment of asthma: A meta- analysis. Current Theraupetic Research 2000; 61:61-73.

23. UKK Pulmonologi IDAI. Konsensus Nasional Penanganan Asma pada Anak. Jakarta, 2000

24. Schuch S, Johnson DW, Callahan S, Canny G, Levison H. Efficacy of frequent nebulized ipratropium bromide added to frequent high-dose albuterol therapy in severe childhood asthma. J Pediatr 1995; 126:639-45.

25. Nuhoglu Y, Bahceeiler, Barlan IB, Basaran MM. The effectiveness of high-dose inhaled budesonide therapy in the treatment of acute asthma exacerbations in children. Ann Allergy Asthma Immunol 2001; 86:318-22.

26. Rabe KF, Vermeire PA, Soriane JB, Maier WC. Clinical management of asthma in 1999: the Asthma insights and reality in Europe (AIRE) study. Eur Respir J 2000; 16:802-7.

27. Condemi JJ, Chervinsky P, Goldstein MF, dkk. Fluticasone propionate powder administration through diskhaler versus triamsolone acetonide aerosol administered through metered-dose inhaler in patients with persistent asthma. J Allergy Clin Immunol 1997; 100: 468-74.

28. Allen HDW, Thong IG, Clifton-Bligh P, Holmes S, Nery L, Wilson KB. Effects of high-dose inhaled corticosteroids on bone metabolism in prepubertal children with asthma. Pediatr Pulmonol 2000; 29:188-93.

29. Kemp JP, Skoner DP, Szefler SJ, Walton-Bowen K, Rivera MC, Smith JA. Once-daily budesonide inhalation suspension for the treatment of persistent asthma in infants and young children. Ann Allergy Asthma Immunol 1999; 83:231-9.

30. Szefler SJ. A review of budesonide inhalation suspension in the treatment of pediatric asthma. Pharmacotherapy 2001; 21:195-206. 